\title{
BK channel activators and their therapeutic perspectives
}

\author{
Bo H. Bentzen ${ }^{1,2 *}$, Søren-Peter Olesen ${ }^{1}$, Lars C. B. Rønn ${ }^{3}$ and Morten Grunnet ${ }^{2,3}$ \\ ${ }^{1}$ Department of Biomedical Sciences, Faculty of Health Sciences, Danish Arrhythmia Research Centre, University of Copenhagen, Copenhagen, Denmark \\ ${ }^{2}$ Acesion Pharma, Copenhagen, Denmark \\ ${ }^{3}$ H. Lundbeck A/S, Copenhagen, Denmark
}

\section{Edited by:}

Thomas M. Weiger, University of Salzburg, Austria

\section{Reviewed by:}

Luis A. Pardo, Max-Planck-Institute of Experimental Medicine, Germany

Fabiana Silvia Scornik, University of Girona, Spain

\section{*Correspondence:}

Bo H. Bentzen, Department of Biomedical Sciences, Faculty of Health Sciences, Danish Arrhythmia Research Centre, University of Copenhagen, Blegdamsvej 3B, DK-2200 Copenhagen, Denmark e-mail: bobe@sund.ku.dk
The large conductance calcium- and voltage-activated $\mathrm{K}^{+}$channel (KCa1.1, BK, MaxiK) is ubiquitously expressed in the body, and holds the ability to integrate changes in intracellular calcium and membrane potential. This makes the BK channel an important negative feedback system linking increases in intracellular calcium to outward hyperpolarizing potassium currents. Consequently, the channel has many important physiological roles including regulation of smooth muscle tone, neurotransmitter release and neuronal excitability. Additionally, cardioprotective roles have been revealed in recent years. After a short introduction to the structure, function and regulation of BK channels, we review the small organic molecules activating BK channels and how these tool compounds have helped delineate the roles of BK channels in health and disease.

Keywords: KCa1.1, BK, MaxiK, KCNMA1, high-conductance calcium-activated potassium channels, activators, openers, pharmacology

\section{INTRODUCTION}

The large conductance calcium- and voltage-activated $\mathrm{K}^{+}$channel (BK, KCa1.1, MaxiK) channel is encoded by a single gene (KCNMA1, SLO-1). Structurally the channel consist of four poreforming BK $\alpha$-subunits, each with 7 transmembrane segments and an extracellular N-terminus. The channel monomer is composed of essentially two distinct modules, one being primarily responsible for voltage-sensing and the other for $\mathrm{Ca}^{2+}$-sensing (Meera et al., 1997).

The BK channel is ubiquitously expressed in the body and represents a unique class of potassium channels, not only because of its high single channel conductance (Butler et al., 1993; Pallanck and Ganetzky, 1994) ( $250 \mathrm{pS}$ measured in symmetrical $\left.\mathrm{K}^{+}\right)$, but also because it can be activated by $\mathrm{Ca}^{2+}$ alone, membrane depolarization alone, or synergistically by both (Magleby, 2003). The ability to integrate changes in intracellular calcium and membrane potential makes the BK channel an important negative feedback system, linking changes in intracellular calcium to outward hyperpolarizing potassium currents. Consequently, the channel has many important roles, including regulation of neurotransmitter release, neuronal excitability and smooth muscle tone (Salkoff et al., 2006). In agreement with this experimental down-regulation of BK in mice is associated with erectile dysfunction, bladder over-activity, urinary incontinence (Meredith et al., 2004; Werner et al., 2005; Sprossmann et al., 2009) and hypertension (Sausbier et al., 2005). In addition, a gain-of-function mutation in KCNMA1 has been reported to result in a syndrome of coexistent generalized epilepsy and paroxysmal dyskinesia in humans (Du et al., 2005); Gain-of-function mutations in the $\beta 1$ subunit were associated with low prevalence of diastolic hypertension (Fernández-Fernández et al., 2004). However, the role of BK channels in epilepsy is not straight forward, as a loss of function mutation has also been associated with temporal lobe epilepsy, as described in detail in the paragraph " $B K$ channels in the central nervous system."

To serve its many diverse roles, and considering its wide tissue distribution, it is not surprising that BK activity is regulated by numerous mechanisms. On the transcriptional level, extensive alternative splicing gives rise to channels with altered $\mathrm{Ca}^{2+}$ sensitivity, channel kinetics, localization and hormone sensitivity (for review see Shipston, 2001). Moreover co-assembly with auxillary subunits including $\beta 1-4$ and leucine-rich repeat-containing proteins (LRRC) changes the channels calcium- and voltagesensitivity, as well as pharmacological properties (Knaus et al., 1994; McManus et al., 1995; Valverde et al., 1999; Wallner et al., 1999; Meera et al., 2000; Yan and Aldrich, 2010, 2012). On the post-translational level, channel activity is regulated by a number of endogenous mediators such as arachidonic acids, $\mathrm{NO}, \mathrm{pH}$ (Avdonin et al., 2003), zinc (Hou et al., 2010), and phosphorylation of the channel (Yan et al., 2008) by protein kinase A, C, G, and CaMKII (Hou et al., 2009; Wang et al., 2013; Hosseinzadeh et al., 2014; Toro et al., 2014). Other modifications such as palmitoylation favor cell surface expression, while myristoylation appear to favor endocytosis (Jeffries et al., 2010; Alioua et al., 2011; Tian et al., 2012). Finally, BK channels have been found to localize to macro-molecular signaling complexes that also contain calcium channels (Grunnet and Kaufmann, 2004; Fakler and Adelman, 2008) or in close proximity to the IP3-receptors and ryanodine receptors (Nelson et al., 1995; Weaver et al., 2007). This colocalization to areas of high local calcium levels adds a regulatory level. Consequently, it is difficult to predict the activity of BK channels in a given cell; but because of their synergistic activation by voltage and calcium, one can assume that pharmacological activation of the channel will tend to potentiate the existing physiological regulatory role that $\mathrm{BK}$ channels play. Hence, under most physiological conditions, drugs that increase the open probability 
of BK channels will promote an efflux of potassium ions upon increases in intracellular $\mathrm{Ca}^{2+}$. This hyperpolarization of cell membranes leads to cellular responses such as decreased cell excitability and smooth muscle relaxation. Due to this, drugs that activate BK channels could represent a novel therapeutic strategy for treatment of certain types of epilepsy, bladder instability, erectile dysfunction, ischemic heart disease and chronic obstructive pulmonary disease. Despite intense academic and industrial focus, no drugs intentionally targeting BK channels are on the market and to the best of our knowledge only one drug (Andolast) is currently in clinical development.

\section{BK CHANNEL ACTIVATORS}

Many different chemical entities have been found to increase the activity of BK channels. Within these entities, differences in calcium dependency, subunit composition and drug binding sites have been found. Based on their origin and structure the chemical entities can be classified in: (A) Endogenous BK channel modulators and structural analogs; (B) Naturally occurring BK channel openers and structural analogs; (C) Synthetic BK channel openers. Only a handful of interesting examples will be provided. For a comprehensive review see Nardi and Olesen (2008).

\section{ENDOGENOUS BK CHANNEL MODULATORS AND STRUCTURAL ANALOGS}

Endogenous chemicals such as arachidonic acid and the metabolites of cytochrome P450, epoxygenase and lipoxygenase, have been found to increase BK channel activity and be important regulators of vascular tone (for review see Félétou, 2009; Hou et al., 2009). Likewise, other unsaturated free fatty acids such as the omega-3 docosahexaenoic acid have also been found to increase BK channel activity (Denson et al., 2000) in an $\beta$-subunit dependent manner (Hoshi et al., 2013a). In vivo studies involving omega-3 docosahexaenoic acid report lowering of blood pressure in anesthetized wild-type, but not in Slo- 1 knockout mice (Hoshi et al., 2013b). Direct activation of BK channels by the sex hormone $17 \beta$-estradiol has also been reported, with its effect being dependent on the presence of the $\beta-1$ subunit (Valverde et al., 1999). 17 $\beta$-estradiol was later shown to protect cardiac cells from ischemia reperfusion injuries via a possible mitochondrial $\mathrm{BK}$ effect, which led the authors to speculate its possible contribution to the increased incidence of post-menopausal heart attack (Ohya et al., 2005). Likewise other steroid hormones also modulate BK channel activity in a $\beta$-subunit dependent manner (King et al., 2006). Later it was found that already marketed drugs such as the xenoestrogen Tamoxifen also displays BK channel activation (Dick et al., 2001). However, the binding site and mechanism of both estrogen and xenoestrogens are still largely unknown. Other drugs on the market targeting CNS excitability and smooth muscle contraction also display BK channel activating properties in the therapeutic concentration range. These include the antiepileptics zonisamide (Huang et al., 2007) and chlorzoxazone (Liu et al., 2003), along with the phosphodiesterase III inhibitor (cilostazol) approved for treatment of intermittent claudication (Wu et al., 2004).

Recently the first peptide BK channel activator was described. Human $\beta$-defensin 2 is an antimicrobial peptide that is important in the innate immune system. It was found to increase the open probability of the BK channel complex when applied in physiologically relevant concentrations, with the effect being dependent on two amino-acids in the $\beta$-1 loop. Interestingly the authors further demonstrated that this peptide was down-regulated in sera from hypertensive patients, and that infusion of human $\beta$ defensin 2 in monkeys significantly reduced blood pressure (Liu et al., 2013).

\section{NATURALLY OCCURRING BK CHANNEL OPENERS AND STRUCTURAL ANALOGS}

Natural occurring BK channel activators are found in herbs, roots, fungi, and leaves, and have been used in folk medicine for treatment of asthma and smooth muscle disorders (Nardi et al., 2003). Isolation of natural occurring compounds revealed several BK channel activators including DHS-I that was found to dramatically increase the open probability of smooth muscle BK channels when applied to the intracellular site (McManus et al., 1993). The effect like many openers was dependent on the presence of $\beta$-1 subunit (McManus et al., 1995).

\section{SYNTHETIC BK CHANNEL OPENERS}

A wealth of synthetic BK channel activators capable of increasing channel open probabilities have been synthesized by a number of companies. NeuroSearch was among the first to report on small molecule BK channel activators such as NS004 (Olesen et al., 1994a). Later, another benzimidazolone in the form of NS1619 was introduced (Olesen et al., 1994b), which turned out to be the most used tool compound for studying the functional effect of BK channels. NS1619 has been used to study the involvement and therapeutic potential in smooth muscle disorders such as pulmonary hypertension (Vang et al., 2010; Revermann et al., 2014), erectile dysfunction (Spektor et al., 2002; González-Corrochano et al., 2013; Király et al., 2013), bladder instability (Soder and Petkov, 2011; La Fuente et al., 2014) and shock-induced vascular hyperactivity (Hu et al., 2014) along with research into migraines (Lu et al., 2014), inflammatory pain (Akerman et al., 2010), and cytoprotection (Xu et al., 2002; Gáspár et al., 2009).

The binding site of NS1619 has not been established. However, a recent report on another BK channel activator, Cym04, found that the activating effects of both drugs were dependent on the S6/RCK (Regulator of Conductance for $\mathrm{K}^{+}$) linker; the sensitivity to both drugs was lost in $\mathrm{BK}$ channel variants with a distinct S6/RCK linker sequence having two deletion mutations. Whether the linker serves as a direct binding site, or is merely important for indirect conformational changes that lead to activation induced by the drug, is not known (Gessner et al., 2012). This linker has previously been proposed to act as a spring that transmits the conformational changes in the RCK upon calcium binding to opening of the channel's gate (Jiang et al., 2002).

The use of NS1619 is however hampered by a relative poor potency, and many off target effects such as inhibition of calcium channels. Consequently, we generated the biarylthiourea NS11021 as a more selective and potent tool compound to study BK channel function. Like many other activators, NS11021 works by shifting the voltage-activation curve of the channel to more negative potentials. At the single channel level this is reflected in 
an increased open probability (Bentzen et al., 2007). This compound has been found to reduce infarct sizes and increase cardiac performance after ischemia, to improve mitochondrial respiration and to protect isolated cardiomyocytes from reperfusion injuries (Bentzen et al., 2009; Aon et al., 2010; Borchert et al., 2013). With regard to studies on smooth muscle dysfunction, NS11021 has been found to enhance erectile responses in rats primarily through its BK activating effects (Kun et al., 2009), and to evoke a pronounced relaxation in small human penile arteries (Király et al., 2013), both equipotent to that induced by the phosphodiesterase type-5 inhibitor sildenafil. In the guinea pig bladder NS11021 decreased excitability and contractility of urinary bladder smooth muscle. This effect was antagonized by iberiotoxin, a selective toxin inhibitor of BK channels (Layne et al., 2010). In the CNS NS11021 has been used to establish a role of BK channels in migraine (Wulf-Johansson et al., 2010; Liu et al., 2014). More recently a new family of $\mathrm{BK}$ channel activators called the GoSlo-SR family was introduced. They are capable of shifting the voltage dependence of BK activation by more than $-100 \mathrm{mV}$ when applied at $10 \mu \mathrm{M}$ to rabbit bladder smooth muscle cells (Roy et al., 2012), with newer derivatives producing the same effects at lower concentrations (Roy et al., 2014). The voltagesensitive dye bis-(1, 3-dibutylbarbituric acid) trimethine oxonol [DiBAC4(3)] at submicromalor levels (Morimoto et al., 2007) produced a shift in the voltage-dependence of the BK channel only when $\beta-1$ and $\beta-4$ subunits were present, whereas saturating concentrations $(30 \mu \mathrm{M})$, produced huge negative shifts by up to $-300 \mathrm{mV}$ in the voltage-dependent activation of BK channels, but this effect was neither dependent on calcium nor the presence of $\beta$-subunits (Scornik et al., 2013). Subunit dependent potency and efficacy was also recently demonstrated for a series of $\mathrm{N}$-arylbenzamide, with loss of effect when $\beta-1$ subunits were co-expressed (Kirby et al., 2013). We recently reported a novel positive BK channel modulator, NS19504 identified in a HTS FLIPR screen (Nausch et al., 2014). This compound represent a novel chemical scaffold and was observed to activate endogenous BK channels in native smooth muscle cells from guinea pig bladder, and to reduce spontaneous contractions in bladder strips in an iberiotoxin-sensitive manner. This suggests NS19504 could serve as a tool to elucidate BK channel function in complex tissues.

Over the last decades a range of structurally distinct synthetic BK channel activators have been produced by different pharmaceutical companies. One of these was BMS204352 that showed neuroprotective effects in animal models (Cheney et al., 2001), and was advanced to phase III clinical trials for the treatment of acute ischemic stroke but failed. A related compound, BMS223131, was shown to relax smooth muscle (Boy et al., 2004) and studied clinically for overactive bladder, but not developed. Other newly synthesized small molecule BK channel activators include thioureas, tetrahydroquinolines, such as compound 36 (Gore et al., 2010) and compound Z (Ponte et al., 2012), terpenes and benzofuroindoles. These were intended mostly for the treatment of urinary incontinence, overactive bladder, erectile dysfunction and stroke, and some of the drugs entered phase I and II clinical trials (for a comprehensive review of synthetic BK channel activators please refer to Nardi and Olesen, 2008). To our knowledge the only BK channel activating drug still considered for clinical development is Andolast. It is neither selective nor potent, but according to the manufacture, Rottapharm, it has shown clinical efficacy and an acceptable safety profile in $\mathrm{mild} /$ moderate asthma. However, phase III clinical trials have not been commenced.

\section{BK CHANNELS IN THE WORKING MYOCARDIUM}

Following a coronary artery occlusion, early restoration of blood perfusion to the ischemic myocardium by reperfusion therapy is of most importance in order to salvage the heart (Keeley et al., 2003). Paradoxically, restoration of blood flow to an ischemic myocardium also causes a so-called reperfusion injury by which cardiac myocytes that were viable immediately before reperfusion die giving rise to an increased infarct size. Because infarct size is recognized as the major determinant of myocardial functional recovery and mortality, any therapy aimed at reducing reperfusion injuries would be appreciated (for review see Yellon and Hausenloy, 2007). In 1986 Murry and colleagues were the first to demonstrate such an intervention when they showed that four short cycles of ischemia interspersed by reperfusion before the sustained ischemic event resulted in a dramatic reduction in infarct size of $\sim 75 \%$ (Murry et al., 1986). The nature of this protective mechanism probably involves cardiac $\mathrm{K}^{+}$channels.

The role of BK channels in cardiomyocytes was for many years neglected because of their absence from the plasma membrane of cardiomyocytes.

However, in 2002 the group of Brian O'Rourke demonstrated the presence of mitochondrial BK channel in cardiomyocytes (Xu et al., 2002). Patch-clamp recordings on mitoplasts from isolated guinea pig cardiomyocytes revealed a voltage- and calcium-dependent potassium current, with a single channel conductance of $307 \mathrm{pS}$ that could be blocked by charybdotoxin, thereby resembling the properties of the plasma membrane BK channel, oriented with its C-terminal facing the mitochondrial matrix. They further demonstrated that mitochondrial uptake of $\mathrm{K}^{+}$was blunted by charybdotoxin and iberiotoxin and accelerated by the BK channel activator NS1619. The molecular identity of the channel remained unknown, but a link to cardioprotection was made by demonstrating that NS1619 when administered prior to the ischemic event, protected isolated perfused rabbit hearts from global ischemia and reperfusion injury, and that this effect was blocked when the BK channel blocker paxilline was coadministered (Xu et al., 2002). Subsequent studies have confirmed that administration of NS1619 protects the heart from ischemiareperfusion injury both in mice (Wang et al., 2004; Redel et al., 2008), rats (Cao et al., 2005; Gao et al., 2005) guinea pigs (Stowe et al., 2006), rabbits (Shi et al., 2007), dogs (Shintani et al., 2004), and in aged rats (Heinen et al., 2014). Likewise, we found that NS11021 protected the heart from ischemia-reperfusion injury when applied prior to, or immediately after ischemia and that this could be antagonized by paxilline (Bentzen et al., 2009).

Because most of the data addressing the role of mitochondrial BK channels rely on pharmacological tools, controversies exist about the importance of mitochondrial BK channels in cardioprotection, as it has been found that both the activators and inhibitors used display unspecific effects. NS1619 at higher 
concentrations directly inhibits L-type $\mathrm{Ca}^{2+}$ channels in rat ventricular myocytes (Park et al., 2007), $\mathrm{Ca}^{2+}$-activated chloride currents (Saleh et al., 2007), and voltage-activated $\mathrm{Ca}^{2+}, \mathrm{K}^{+}$, and $\mathrm{Na}^{+}$channels (Edwards et al., 1994; Olesen et al., 1994b; Holland et al., 1996). Moreover, Cancherini et al. demonstrated that NS1619 also display non-ion channel effects on mitochondria, which they claim could explain some of the cardioprotective effects of NS1619 (Cancherini et al., 2007). A study using the cardioprotective BK channel activator NS11021, found that in nanomolar concentration NS11021 displayed beneficial effects on mitochondria, whereas when the concentration was increased, unspecific effects not related to mitochondrial BK channels were observed (Aon et al., 2010). Interestingly, a methylated analog of NS11021 that is inactive on BK channel, and does not provide cardioprotection (Bentzen et al., 2010) still possesses the unspecific effects on mitochondria of NS11021. This supports the notion that the cardioprotection mediated by NS11021 is BK channel related and not caused by the unspecific effects of the compound (Aon et al., 2010).

With regards to the $\mathrm{BK}$ channel inhibitors used as tool compounds for studying cardioprotection, there is concern about the use paxilline as it has been found at higher concentrations to inhibit the sarco/endoplasmatic reticulum $\mathrm{Ca}^{2+}$-ATPase (SERCA) (Bilmen et al., 2002). Moreover, the cardioprotective effects of the BK channel activator isoflurane were abolished by paxilline both in wild-type and in KCNMA1 $1^{-/-}$hearts, arguing for unspecific effects of paxilline (100). In addition, this study also suggested a dispensable role for KCNMA1 in both mitochondrial $\mathrm{K}^{+}$transport and cardioprotection. Instead, using C. elegans as a model system they found that the related $\mathrm{K}^{+}$channel Slo- 2 was required for mitochondrial $\mathrm{K}^{+}$transport and cardioprotection.

Recently a study by Singh et al. helped to settle the controversies about the pharmacology and role of mitochondrial BK channels in cardioprotection, as they describe the molecular identity of the mitochondrial BK channel. They found that the mitochondrial BK channel in the heart is encoded by a splice variant (VEDEC) of the plasma membrane KCNMA1, and that it holds a 50-aa splice insert which they report is essential for trafficking to the mitochondria. Moreover they also demonstrated that the cardioprotection offered by NS1619 was lost in KCNMA1 KO mice (Singh et al., 2013), cementing the involvement of BK channels in the cardioprotection conferred by NS1619.

Additionally, Soltysinska et al. recently report electrophysiological evidence for a BK-mediated current of $190 \mathrm{pS}$ in mitoplasts from wild-type but not KCNMA1 ${ }^{-/-}$cardiomyocytes. Moreover, changes in reactive oxygen species (ROS) production and attenuated oxidative phosphorylation capacities in $\mathrm{KCNMA1}^{-/}$cardiomyocytes were observed. This suggests a mitochondrial role of KCNMA1 encoded BK channels in fine-tuning the oxidative state of the cell (Soltysinska et al., 2014).

The discrepancy between these two studies demonstrating a role of KCNMA1 in mitochondria and cardioprotection and the earlier work by Wojtovich on Slo-2 where they found KCNMA1 to be dispensable cannot be easily resolved; it should be remembered that different genetic models and experimental procedures were utilized in conducting the research. Moreover, as the authors also state, their results do neither preclude the presence of KCNMA1 in the mitochondria nor a role for KCNMA1 channels in other protective paradigms (Wojtovich et al., 2011).

It is difficult to imagine how the mitochondrial BK channel can at all function considering the negative inner mitochondrial membrane potential in the range of $-180 \mathrm{mV}$. However, the phosphorylation state of the channel, the presence of auxillary subunits such as $\beta-1$ (Ohya et al., 2005), $\beta-4$ (Piwonska et al., 2008; Fretwell and Dickenson, 2009; Skalska et al., 2009) and perhaps LRRCs, could allow for channel activation under physiological and pathophysiological conditions, although the role of LRRCs needs to be explored further. Moreover, considering the high single channel conductance and the large driving force for $\mathrm{K}^{+}$entry, a too high open probability would be detrimental for the mitochondria, as the influx of $\mathrm{K}^{+}$to the matrix would depolarize the mitochondria. Therefore, the channel needs to be present in low abundance and/or with a tightly controlled open probability so that channel activation does not dissipate the proton motive force and ionic homeostasis.

How opening of mitochondrial BK channels confer cardioprotection is largely unknown, but could take place by affecting one or more of the following parameters:

1. Mitochondrial calcium accumulation: $\mathrm{K}^{+}$influx leads to a partial depolarization of the inner membrane potential (Aon et al., 2010). This will reduce the driving force for calcium entry, thereby reducing calcium overload during ischemia (Sato et al., 2005; Stowe et al., 2006). Indeed Stowe et al. found that pre-treatment with the BK channel activation by NS1619 in isolated perfused guinea pig hearts attenuated mitochondrial calcium accumulation following an ischemic event (Stowe et al., 2006). Moreover Singh et al. recently demonstrated that pre-treatment with NS1619 increased the $\mathrm{Ca}^{2+}$ retention capacity of mitochondria, and that this effect was lost in KCNMA1 ${ }^{-/-}$mice (Singh et al., 2013).

2. ROS production: Studies on isolated mitochondria from hearts and neurons have demonstrated a reduced ROS production following stimulation with NS1619, along with the putative activator of mitochondrial BK channels, CGS7184 (Heinen et al., 2007; Kulawiak et al., 2008). This finding was confirmed in isolated heart studies (Stowe et al., 2006). Moreover, using isolated cadiomyocyte mitochondria from KCNMA1 $1^{-/-}$mice it was found that the absence of BK channels resulted in elevated post-anoxic ROS levels (Soltysinska et al., 2014).

3. ATP preservation: Opening the mitochondrial BK channel has been shown to improve mitochondrial energy production, likely via swelling of the mitochondrial matrix (Aon et al., 2010). Likewise, genetically engineered loss of BK channels have been found to attenuate oxidative phosphorylation capacity (Soltysinska et al., 2014).

Taken together, at reperfusion, the improved oxidative phosphorylation, reduced ROS and mitochondrial calcium levels would prevent activation of the mitochondrial permeability transition pore (MPTP), which would otherwise lead to a non-selective permeabilization of the inner mitochondrial membrane resulting in 
mitochondrial collapse, termination of ATP synthesis and cell death (Szabo and Zoratti, 2014).

Indeed, experiments on mitochondria isolated from the brain have demonstrated that opening of MPTP is accelerated in the presence of iberiotoxin (Cheng et al., 2008).

The recent findings using genetically engineered models have clearly demonstrated that KCNMA1 is important for cardioprotection and mitochondrial function. However, much exploration is still needed in order to understand the physiological role of mitochondrial BK channels and how they confer cardioprotection.

From a therapeutic perspective, the recent findings are encouraging and help to clarify the role of BK channel activators in cardioprotection. Considering the importance of BK channels in controlling vascular tone, and their role in intra-cardiac neurons (Pérez et al., 2013; Wojtovich et al., 2013) it is also important to understand how, and if these extra-cardiac BK channels contribute to cardioprotection. Somewhat surprising, and to the best of our knowledge, little research has been undertaken to explore the importance of BK channel mediated flow changes in cardioprotection. Future work using tissue specific knock-down of KCNMA1 could shed light on this interesting aspect.

\section{BK CHANNELS IN BLADDER FUNCTION}

The BK channel $\alpha$-pore forming subunit and auxillary $\beta$-1 and $\beta-4$ subunits are expressed in urinary bladder smooth muscle (UBSM) cells (Ohya et al., 2000; Ohi et al., 2001; Petkov et al., 2001; Werner et al., 2007; Chen and Petkov, 2009; Hristov et al., 2011), where BK channels have been shown to be important regulators of bladder contractility and excitability (reviewed in Petkov, 2014).

One line of studies has demonstrated that inhibition of BK channel function markedly affects bladder function. Thus, the BK channel blockers iberiotoxin and paxilline have been shown to increase contractility in detrusor smooth muscle strips from humans (Darblade et al., 2006; La Fuente et al., 2014), pigs (Buckner et al., 2002), guinea pigs (Heppner et al., 1997; Kobayashi et al., 2000; Mora and Suarez-Kurtz, 2005), rats (Uchida et al., 2005), and mice (Herrera et al., 2005) when stimulated electrically or pharmacologically.

In addition, support for a role of BK channels in bladder function has been provided by genetic mouse models. In bladder strips from BK deficient mice lacking the BK pore forming $\alpha$-subunit, contractility has been found to be markedly increased in response to both cholinergic and purinergic stimulation. This is reflected in a lower frequency of electrical stimulation required to elicit a contraction (Thorneloe et al., 2005; Werner et al., 2007). In vivo, KCNMA1 $1^{-/-}$mice without functional BK-expression show a pronounced increase in voiding frequency and the occurrence of non-voiding bladder contractions. The mice have increased average bladder pressure and decreased void volume (Meredith et al., 2004; Thorneloe et al., 2005).

Mice deficient in the BK subunit $\beta-1$, the predominant accessory subunit in smooth muscle cells show moderate hypertension (Brenner et al., 2000; Plüger et al., 2000). Bladder strips from these mice showed increased amplitude and decreased frequency of phasic contraction similar to strips from WT mice treated with iberiotoxin. However, an additional response to iberiotoxin was still present in strips from KO mice (Petkov et al., 2001). Thus, studies on $\mathrm{BK} \beta-1 \mathrm{KO}$ mice support a role of $\mathrm{BK}$ and specifically the $\beta-1$ subunit in modulation of smooth muscle contractility in the cardiovascular system and bladder.

Taken together, there is considerable support that inhibition or block of BK function adversely affects bladder function, increasing contractility in mice in vivo and in isolated bladder preparations from several species including mice, guinea pigs, and humans. This could suggest that increased BK channel activity in the bladder may counteract excessive detrusor contractions in bladder overactivity. Indeed, in pharmacological studies, positive modulation of BK channels by means of small molecules including NS-8, NS1608, and NS1619, have been shown to at varying degrees to reduce contractility of bladder strips from rats, guinea pigs, pigs (Imai et al., 2001; Malysz et al., 2004; Mora and Suarez-Kurtz, 2005), and humans (La Fuente et al., 2014). In one study, NS8 and NS1619 reduced rat bladder and aorta contractility with approximately similar potency (Malysz et al., 2004); while in another study, using NS-8, a clear selectivity for rat bladder over portal vein was reported. This supports the notion of BK channels being an attractive target in overactive bladder and urgency urinary incontinence. NS-8 was also reported to increase bladder capacity in urethane-anaesthetized rats after duodenal administration (Nicot et al., 1992).

In detrusor myocytes, BK channels may be activated both by increases in internal $\mathrm{Ca}^{2+}$ mediated via voltage-dependent L-type calcium channels and transiently by ryanodine receptors mediating local " $\mathrm{Ca}^{2+}$ sparks" as shown by patch clamp in guinea pig and human myocytes (Ohi et al., 2001; Herrera and Nelson, 2002; Hristov et al., 2011; Malysz et al., 2013). BK channels are thereby thought to mediate a negative feedback to limit contractions of the detrusor smooth muscle (Herrera et al., 2000, 2005) and to regulate patterns of spontaneous phasic contractions. Thus, in human UBSM cells BK channel outward currents have been shown to be a major determinant of repolarization following action potentials. Moreover, BK channel activity is also an important regulator of the resting potential and spontaneous phasic contraction amplitude, as well as the amplitude of electric field stimulation-induced contractions in UBSM strips (Hristov et al., 2011).

Spontaneous non-voiding contractions have been associated with bladder overactivity (Brading, 1997; Andersson, 2010); Inhibition of spontaneous phasic contractions, with minimal effect on voiding contractions have been suggested as a favorable profile in myogenic bladder overactivity. Interestingly, decreased BK channel $\alpha$ - and $\beta$-subunit expression have been reported in tissue from prostate patient bladders with detrusor overactivity, when compared with patients with similar obstruction but without detrusor overactivity (Chang et al., 2010). Therefore, positive modulation of BK channels may represent a strategy to alleviate bladder overactivity and increased detrusor contractility. The BK channel modulators NS11021 and NS19504 have been studied in guinea pig strips, and shown to potently inhibit spontaneous phasic contractions with more modest effects on contractions induced by electric field stimulation (Layne et al., 2010; Nausch et al., 2014). This supports the potential of BK 
openers to normalize detrusor function in bladder overactivity with minimal effect on voiding contractions.

BK channel openers have also been suggested as a strategy to alleviate bladder overactivity of neurogenic origin. Interestingly, decreased BK UBSM expression, increased contractility and increased excitability in cells from humans with neurogenic detrusor overactivity have been reported (Hristov et al., 2013). However, in a study of the BK opener NS1619, effect on spontaneous contractions was only observed in detrusor strips from normal subjects, not in strips from patients with neurogenic bladder overactivity (Oger et al., 2011). In another study using isolated human UBSM cells and strips from subjects without prior history of overactive bladder, NS1619 was found to inhibit myogenic and nerve-evoked contractions (Hristov et al., 2012).

The underlying pathophysiology in overactive bladder is often not well understood and may be multifactorial, depending on both myogenic and neurogenic factors (Hanna-Mitchell et al., 2013). In addition to being a major regulator of UBSM contractility and excitability, BK channels may also be important for bladder afferent nerve activity and urothelial function. However, the role of BK channels in specific pathophysiologies associated with bladder overactivity are not known. Regulation of BK channel activity is complex; in the bladder it is regulated by voltage levels, calcium levels, kinase activity and by the action of signal molecules involved in dysregulation of UBSM function (Hristov et al., 2014). It was recently reported that BK channel activity mediates PGE2 induced increase in spontaneous phasic contractions in detrusor strips (Parajuli et al., 2014a). BK channel activity has also been linked functionally to changes in $\mathrm{Ca}^{2+}$ signaling and detrusor contractility induced by cAMP (Xin et al., 2014) and muscarinergic receptor activation (Parajuli et al., 2014b).

BK channel openers have been advanced to clinical studies for bladder dysfunction, but have so far not reached the market. TA1702 (structure not disclosed) has been in Phase I by GSK under license from Tanabe. Although no public announcements have been made about withdrawal, it does not currently appear in the company's development pipeline. Nippon-Shinyaku discontinued development of NS-8 for overactive bladder (Announced Jan $16,2007)$ due to lack of efficacy in proof-of-concept study with Apogepha. NS-8 reached Phase II in Europe and Phase I in Japan. A number of new BK openers representing new chemical scaffolds and showing improved selectivity have been reported, and may be promising leads for future development within bladder dysfunction.

Taken together, there is strong support that positive modulators of BK may have beneficial effect in instable or overactive bladder, without compromising normal voiding functions. Further studies using recently discovered BK openers, that possess improved selectivity are needed to translate findings from animal models to the human bladder, and to elucidate the potential for BK modulators in bladder overactivity disorders of myogenic or neurogenic origin.

\section{BK CHANNELS IN THE CENTRAL NERVOUS SYSTEM}

BK channels are abundantly expressed in the central nervous system (CNS) with various functions being associated to these channels in neurons. The channels are expressed in specific neurons, with subcellular localizations in presynaptic terminals, soma and dendrites (Knaus et al., 1996). As mentioned previously BK channels are distinctive among ion channels, being gated by both voltage and intracellular $\mathrm{Ca}^{2+}$. This gating mechanism, in combination with their close proximity or even physical coupling to voltage-gated $\mathrm{Ca}^{2+}$ channels, makes $\mathrm{BK}$ channels potentially important components in negative feed-back mechanisms (Marrion and Tavalin, 1998; Grunnet and Kaufmann, 2004). In a situation of excessive $\mathrm{Ca}^{2+}$ influx e.g., in pre-synaptic terminals and corresponding disproportionate transmitter release, activation of $\mathrm{BK}$ channels by incoming $\mathrm{Ca}^{2+}$ will counterbalance this effect by hyperpolarizing the membrane, and thereby shut off voltage-dependent $\mathrm{Ca}^{2+}$ influx. In other words, BK channels can be seen as an "emergency break," which prevents transmitter related hyperexcitability and concomitant cell toxicity. An example of this is observed in Purkinje cells in the cerebellum (Swensen and Bean, 2003; Womack and Khodakhah, 2004). From the somatic localization, BK channels are thought to exert their function by shaping the repolarization and thereby after-hyperpolarization (AHP) of action potentials. The afterhyperpolarization is divided into three phases; a fast (fAHP), an intermediate (mAHP) and a slow (sAHP) part. BK channels participate in the fast phase and have been especially well studied in the CA1 region of the hippocampus, where fAHP is inhibited by addition of TEA and the more selective BK inhibitor iberiotoxin (Storm, 1987). It should be mentioned that BK $\alpha$-subunit knockout mice are viable, but have several phenotypes that include CNS related functions. Among these are ataxia and high frequency hearing loss (Salkoff et al., 2006).

The localization of BK channels in Purkinje cells from the cerebellum points to the important role of BK in motor coordination, since Purkinje neurons are the sole output of the cerebellar cortex. As a consequence KCNMA1 (-/-) knock-out mice have impaired motor coordination and ataxia (Sausbier et al., 2004). These results have later been consolidated in transgenic mice lacking BK channels exclusively in the Purkinje cells of the cerebellum (Chen et al., 2010). BK channel impact on locomotor impairments may also rely on the channel expression in basal ganglia, where prominent expression of BK channels has been demonstrated in substantia nigra, pars reticulate, globus pallidus, and entopeduncular nucleus. All these areas have a potential impact on the pathophysiology of tremors and ataxia (Sausbier et al., 2006).

An auditory phenotype of the BK knock-outs also points to a function of the channels in hearing. When knocking out the BK $\alpha$-subunit, but not the $\beta$-subunit, a resulting progressive hearing loss is observed. Hearing loss at high frequencies is evident, but only after 8 weeks of age and onward. This point to irreversible progressive loss of cochlear outer hair cells. A similar phenotype can be observed by genetic deletion or pharmacological inhibition of the voltage-dependent potassium channel KCNQ4 (Jentsch, 2000; Rüttiger et al., 2004).

BK channels have also been associated to circadian rhythms. Circadian rhythms in mammals are driven by a central oscillator in the hypothalamic suprachiasmatic nucleus (SCN). This nucleus is constituted by relatively few (about 10,000) neurons that are characterized to oscillate in a $24 \mathrm{~h}$ rhythms. These cells 
are unique in the sense that they can generate rhythms. The SCN neurons are central in understanding the pathophysiology of sleep and circadian diseases; these neurons are innervated from the retina and this projection is essential in setting the clock to the external light-dark regimen (entrainment). Entrainment maintains the internal rhythms of exactly $24 \mathrm{~h}$.

BK channels have been suggested as a novel and attractive target for sleep and circadian diseases (Meredith et al., 2006). BK channels are expressed in the SCN, and the expression of KCNMA1 (BK $\alpha$-subunit) mRNA is regulated in a diurnal manner. Most interestingly, KCNMA1 deficient mice have a larger amplitude in electrical activity of SCN neurons. The same mice had a weak rhythm in locomotor behavior. Taken together, these data suggest that BK modulators could influence the endogenous rhythm structure, and perhaps be useful in patients with circadian and sleep dysfunctions.

BK channels have also been associated to various epileptogenic phenotypes but the picture is not straight forward. In its simplest term, inhibition of BK channels should result in general depolarization and thereby hyperexcitability. Consequently it could be expected that epilepsy could be treated with pharmacological activation of BK channels. There is evidence of BK loss-of-function in relation to epilepsy, however to tamper the picture also $\mathrm{BK}$ gain-of-function has been linked to the disease. In preclinical models of inherited generalized tonic-clonic epilepsy and temporal lobe epilepsy (TLE) animals demonstrated a reduction in AHP. This decrease was suggested to be due to a reduction in $\mathrm{Ca}^{2+}$ dependent $\mathrm{K}^{+}$conductance, that could be related to BK channels, but the exact nature of the specific conductance was not addressed by application of specific pharmacological tools (Verma-Ahuja et al., 1995). Also in a pharmacological TLE model, application of the muscarinic receptor agonist pilocarpine produced a down regulation of $\mathrm{BK}$ channels, especially in the hippocampus and cortex (Pacheco Otalora et al., 2008). The picture is blurred by the fact that BK channel gain-of-function, at least as a consequence of $\beta 4$-subunit knock-out, that leads to an overall increase in BK activity, can result in TLE (Brenner et al., 2005). Reports in favor of increased BK activity as a cause for epilepsy, are observations that gain-of-function BK channels can result in generalized tonic-clonic seizures (Shruti et al., 2008). Target engagement in these findings was substantiated by application of paxilline that could suppress the epileptogenic phenotype (Sheehan et al., 2009).

When it comes to clinical evidence of BK channel functions, CNS is actually one of the only areas where reports exist. The first associations between BK activity and epilepsy in patients were concomitant, with the general notion of loss of BK channel activity as the underlying cause of hyperactivity and epilepsy. In TLE patients a reduction in FAHP and a down-regulation of BK channels was observed (N'Gouemo, 2011). Again the picture is distorted by the fact that human absence epilepsy and idiopathic generalized epilepsy are directly associated to a BK channel gainof-function mutation (Du et al., 2005). The gain-of-function is a single amino acid substitution (D434G) in the BK $\alpha$-subunit, that among other things, increases $\mathrm{Ca}^{2+}$ sensitivity and mean open time of the channel (Du et al., 2005). These observations are good examples of how the prediction of the physiological outcome of a certain ion channel mutation can be very difficult. The intuitive feeling will be that increasing a potassium conductance and thereby hyperpolarizing a cell membrane should dampen cellular excitability. However, in intact cell system this logic rational is challenged by the fact that hyperpolarization will result in more efficient release of $\mathrm{Na}^{+}$channels from inactivation, resulting in a higher number of $\mathrm{Na}^{+}$channels being available for activation in a subsequent action potential. The exact phenotype of a given ion channel mutation, will therefore always be the sum of the orchestrated activity of a number of different ion channels, in combination with other membrane proteins and the entire cellular machinery. When considering CNS it should also be kept in mind that the brain consists of both excitable and inhibitory neurons, and the exact interplay between neuronal circuits and cellular and subcellular positions of the mutated proteins will impact the final phenotype of any given mutation.

\section{CONCLUDING REMARKS}

It is now two decades since the first small molecule BK channel opener was reported. Over these years a wealth of BK channel openers, including naturally occurring and synthetic compounds have been discovered, and recently the first peptide opener of BK channels was disclosed (Liu et al., 2013). The structural diversity of these molecules is also reflected in their mode of action. Some compounds display $\beta$-subunit dependency (Valverde et al., 1999), whereas others are dependent upon intracellular calcium concentrations (Bentzen et al., 2007).

The pharmaceutical interest in BK channel activators has been spurred on by the last decade's biological research, reporting the important roles of BK channels in both health and disease. By integrating changes in intracellular calcium and membrane potential, the BK channel serves as an important negative feedback system, linking increases in intracellular calcium to outward hyperpolarizing potassium current. Using BK channel openers, evidence of the channels role and possible therapeutic potential has been established with respect to a number of indications, characterized by hyper excitability and smooth muscle dysfunction. Despite vast amounts of preclinical work and basic research, clinical evidence for the usefulness of BK channel openers is still missing and clinical development of BK channel activators has in large been discontinued and is to our knowledge currently not taking place except for Andolast. Translating preclinical findings to the clinic is tough, with failure being caused by many factors. However, the lack of potency and especially the poor selectivity of compounds toward off-targets are troublesome, as it can obscure preclinical proof-of-concept findings. Despite substantial amount of in vitro based BK pharmacology literature, it is striking how few in vivo evaluations have been published. Although only speculative, this could point to the challenges for in vivo applications of many BK activators, thereby also adding to the lack of successful clinical attempts to reveal the potential for BK activators. Therefore, a need for more potent, selective and in vivo applicable compounds is still warranted.

\section{AUTHOR CONTRIBUTIONS}

All authors contributed to the drafting, writing, revising, and approval of the manuscript. 


\section{ACKNOWLEDGMENT}

This work was financially supported by The Danish National Research Foundation.

\section{REFERENCES}

Akerman, S., Holland, P. R., Lasalandra, M. P., and Goadsby, P. J. (2010). Inhibition of trigeminovascular dural nociceptive afferents by $\mathrm{Ca}(2+)$ activated $\mathrm{K}(+)($ MaxiK/BK $(\mathrm{Ca}))$ channel opening. Pain 151, 128-136. doi: 10.1016/j.pain.2010.06.028

Alioua, A., Li, M., Wu, Y., Stefani, E., and Toro, L. (2011). Unconventional myristoylation of large-conductance $\mathrm{Ca}^{2+}$-activated $\mathrm{K}^{+}$channel (Slo1) via serine/threonine residues regulates channel surface expression. Proc. Natl. Acad. Sci. U.S.A. 108, 10744-10749. doi: 10.1073/pnas.1008863108

Andersson, K.-E. (2010). Detrusor myocyte activity and afferent signaling. Neurourol. Urodyn. 29, 97-106. doi: 10.1002/nau.20784

Aon, M. A., Cortassa, S., Wei, A.-C., Grunnet, M., and O'Rourke, B. (2010). Energetic performance is improved by specific activation of $\mathrm{K}+$ fluxes through $\mathrm{K}(\mathrm{Ca})$ channels in heart mitochondria. Biochim. Biophys. Acta 1797, 71-80. doi: 10.1016/j.bbabio.2009.08.002

Avdonin, V., Tang, X. D., and Hoshi, T. (2003). Stimulatory action of internal protons on Slo1 BK channels. Biophys. J. 84, 2969-2980. doi: 10.1016/S00063495(03)70023-X

Bentzen, B. H., Andersen, R. W., Olesen, S.-P., Grunnet, M., and Nardi, A. (2010). Synthesis and characterisation of NS13558: a new important tool for addressing KCal. 1 channel function ex vivo. Naunyn Schmiedebergs Arch. Pharmacol. 381, 271-283. doi: 10.1007/s00210-009-0456-2

Bentzen, B. H., Nardi, A., Calloe, K., Madsen, L. S., Olesen, S.-P., and Grunnet, M. (2007). The small molecule NS11021 is a potent and specific activator of Ca2+activated big-conductance K+ channels. Mol. Pharmacol. 72, 1033-1044. doi: 10.1124/mol.107.038331

Bentzen, B. H., Osadchii, O., Jespersen, T., Hansen, R. S., Olesen, S.-P., and Grunnet, M. (2009). Activation of big conductance Ca2+-activated K+ channels (BK) protects the heart against ischemia-reperfusion injury. Pflügers Arch. 457, 979-988. doi: 10.1007/s00424-008-0583-5

Bilmen, J. G., Wootton, L. L., and Michelangeli, F. (2002). The mechanism of inhibition of the sarco/endoplasmic reticulum Ca2+ ATPase by paxilline. Arch. Biochem. Biophys. 406, 55-64. doi: 10.1016/S0003-9861(02)00240-0

Borchert, G. H., Hlaváčková, M., and Kolář, F. (2013). Pharmacological activation of mitochondrial $\mathrm{BK}(\mathrm{Ca})$ channels protects isolated cardiomyocytes against simulated reperfusion-induced injury. Exp. Biol. Med. (Maywood) 233-241. doi: $10.1177 / 1535370212474596$

Boy, K. M., Guernon, J. M., Sit, S.-Y., Xie, K., Hewawasam, P., Boissard, C. G., et al. (2004). 3-Thio-quinolinone maxi-K openers for the treatment of erectile dysfunction. Bioorg. Med. Chem. Lett. 14, 5089-5093. doi: 10.1016/j.bmcl.2004. 07.080

Brading, A. F. (1997). A myogenic basis for the overactive bladder. Urology 50(Suppl. 6A), 57-67. discussion: 68-73.

Brenner, R., Chen, Q. H., Vilaythong, A., Toney, G. M., Noebels, J. L., and Aldrich, R. W. (2005). BK channel beta4 subunit reduces dentate gyrus excitability and protects against temporal lobe seizures. Nat. Neurosci. 8, 1752-1759. doi: 10.1038/nn1573

Brenner, R., Peréz, G. J., Bonev, A. D., Eckman, D. M., Kosek, J. C., Wiler, S. W., et al. (2000). Vasoregulation by the betal subunit of the calcium-activated potassium channel. Nature 407, 870-876. doi: 10.1038/35038011

Buckner, S. A., Milicic, I., Daza, A. V., Coghlan, M. J., and Gopalakrishnan, M. (2002). Spontaneous phasic activity of the pig urinary bladder smooth muscle: characteristics and sensitivity to potassium channel modulators. $\mathrm{Br}$. J. Pharmacol. 135, 639-648. doi: 10.1038/sj.bjp.0704499

Butler, A., Tsunoda, S., McCobb, D. P., Wei, A., and Salkoff, L. (1993). mSlo, a complex mouse gene encoding "maxi" calcium-activated potassium channels. Science 261, 221-224. doi: 10.1126/science.7687074

Cancherini, D. V., Queliconi, B. B., and Kowaltowski, A. J. (2007). Pharmacological and physiological stimuli do not promote $\mathrm{Ca}(2+)$-sensitive $\mathrm{K}+$ channel activity in isolated heart mitochondria. Cardiovasc. Res. 73, 720-728. doi: 10.1016/j.cardiores.2006.11.035

Cao, C.-M., Xia, Q., Gao, Q., Chen, M., and Wong, T.-M. (2005). Calciumactivated potassium channel triggers cardioprotection of ischemic preconditioning. J. Pharmacol. Exp. Ther. 312, 644-650. doi: 10.1124/jpet.104.074476
Chang, S., Gomes, C. M., Hypolite, J. A., Marx, J., Alanzi, J., Zderic, S. A., et al. (2010). Detrusor overactivity is associated with downregulation of largeconductance calcium- and voltage-activated potassium channel protein. Am. J. Physiol. Renal Physiol. 298, F1416-F1423. doi: 10.1152/ajprenal.00595.2009

Chen, M., and Petkov, G. V. (2009). Identification of large conductance calcium activated potassium channel accessory beta4 subunit in rat and mouse bladder smooth muscle. J. Urol. 182, 374-381. doi: 10.1016/j.juro.2009.02.109

Chen, X., Kovalchuk, Y., Adelsberger, H., Henning, H. A., Sausbier, M., Wietzorrek, G., et al. (2010). Disruption of the olivo-cerebellar circuit by Purkinje neuronspecific ablation of BK channels. Proc. Natl. Acad. Sci. U.S.A. 107, 12323-12328. doi: 10.1073/pnas.1001745107

Cheney, J. A., Weisser, J. D., Bareyre, F. M., Laurer, H. L., Saatman, K. E., Raghupathi, R., et al. (2001). The maxi-K channel opener BMS-204352 attenuates regional cerebral edema and neurologic motor impairment after experimental brain injury. J. Cereb. Blood Flow Metab. 21, 396-403. doi: 10.1097/00004647-200104000-00008

Cheng, Y., Gu, X. Q., Bednarczyk, P., Wiedemann, F. R., Haddad, G. G., and Siemen, D. (2008). Hypoxia increases activity of the BK-channel in the inner mitochondrial membrane and reduces activity of the permeability transition pore. Cell. Physiol. Biochem. 22, 127-136. doi: 10.1159/000149790

Darblade, B., Behr-Roussel, D., Oger, S., Hieble, J.-P., Lebret, T., Gorny, D., et al. (2006). Effects of potassium channel modulators on human detrusor smooth muscle myogenic phasic contractile activity: potential therapeutic targets for overactive bladder. Urology 68, 442-448. doi: 10.1016/j.urology.2006.03.039

Denson, D. D., Wang, X., Worrell, R. T., and Eaton, D. C. (2000). Effects of fatty acids on BK channels in $\mathrm{GH}(3)$ cells. Am. J. Physiol. Cell Physiol. 279, C1211-C1219.

Dick, G. M., Rossow, C. F., Smirnov, S., Horowitz, B., and Sanders, K. M. (2001). Tamoxifen activates smooth muscle BK channels through the regulatory beta 1 subunit. J. Biol. Chem. 276, 34594-34599. doi: 10.1074/jbc.M104689200

Du, W., Bautista, J. F., Yang, H., Diez-Sampedro, A., You, S.-A., Wang, L., et al. (2005). Calcium-sensitive potassium channelopathy in human epilepsy and paroxysmal movement disorder. Nat. Genet. 37, 733-738. doi: 10.1038/ng1585

Edwards, G., Niederste-Hollenberg, A., Schneider, J., Noack, T., and Weston, A H. (1994). Ion channel modulation by NS1619, the putative BKCa channel opener, in vascular smooth muscle. Br. J. Pharmacol. 113, 1538-1547. doi: 10.1111/j.1476-5381.1994.tb17171.x

Fakler, B., and Adelman, J. P. (2008). Control of K(Ca) channels by calcium nano/microdomains. Neuron 59, 873-881. doi: 10.1016/j.neuron.2008.09.001

Félétou, M. (2009). Calcium-activated potassium channels and endothelial dysfunction: therapeutic options? Br. J. Pharmacol. 156, 545-562. doi: 10.1111/j.1476-5381.2009.00052.x

Fernández-Fernández, J. M., Tomás, M., Vázquez, E., Orio, P., Latorre, R., Sentí, M., et al. (2004). Gain-of-function mutation in the KCNMB1 potassium channel subunit is associated with low prevalence of diastolic hypertension. J. Clin. Invest. 113, 1032-1039. doi: 10.1172/JCI200420347

Fretwell, L., and Dickenson, J. M. (2009). Role of large-conductance $\mathrm{Ca}(2+)$ -activated potassium channels in adenosine $\mathrm{A}(1)$ receptor-mediated pharmacological preconditioning in H9c2 cells. Eur. J. Pharmacol. 618, 37-44. doi: 10.1016/j.ejphar.2009.07.008

Gao, Q., Zhang, S.-Z., Cao, C.-M., Bruce, I. C., and Xia, Q. (2005). The mitochondrial permeability transition pore and the $\mathrm{Ca} 2+$-activated $\mathrm{K}+$ channel contribute to the cardioprotection conferred by tumor necrosis factor-alpha. Cytokine 32, 199-205. doi: 10.1016/j.cyto.2005.09.008

Gáspár, T., Domoki, F., Lenti, L., Katakam, P. V. G., Snipes, J. A., Bari, F., et al. (2009). Immediate neuronal preconditioning by NS1619. Brain Res. 1285 196-207. doi: 10.1016/j.brainres.2009.06.008

Gessner, G., Cui, Y.-M., Otani, Y., Ohwada, T., Soom, M., Hoshi, T., et al. (2012). Molecular mechanism of pharmacological activation of BK channels. Proc. Natl. Acad. Sci. U.S.A. 109, 3552-3557. doi: 10.1073/pnas.1114321109

González-Corrochano, R., La Fuente, J., Cuevas, P., Fernández, A., Chen, M., Sáenz de Tejada, I., et al. (2013). Ca2+ -activated K+ channel (KCa) stimulation improves relaxant capacity of PDE5 inhibitors in human penile arteries and recovers the reduced efficacy of PDE5 inhibition in diabetic erectile dysfunction. Br. J. Pharmacol. 169, 449-461. doi: 10.1111/bph.12143

Gore, V. K., Ma, V. V., Yin, R., Ligutti, J., Immke, D., Doherty, E. M., et al. (2010). Structure-activity relationship (SAR) investigations of tetrahydroquinolines as BKCa agonists. Bioorg. Med. Chem. Lett. 20, 3573-3578. doi: 10.1016/j.bmcl.2010.04.125 
Grunnet, M., and Kaufmann, W. A. (2004). Coassembly of big conductance Ca2+activated $\mathrm{K}+$ channels and L-type voltage-gated $\mathrm{Ca} 2+$ channels in rat brain. J. Biol. Chem. 279, 36445-36453. doi: 10.1074/jbc.M402254200

Hanna-Mitchell, A. T., Kashyap, M., Chan, W. V., Andersson, K.-E., and Tannenbaum, C. (2013). Pathophysiology of idiopathic overactive bladder and the success of treatment: a systematic review from ICI-RS. Neurourol. Urodyn. 33, 611-617. doi: 10.1002/nau.22582

Heinen, A., Aldakkak, M., Stowe, D. F., Rhodes, S. S., Riess, M. L., Varadarajan, S. G., et al. (2007). Reverse electron flow-induced ROS production is attenuated by activation of mitochondrial Ca2+-sensitive $\mathrm{K}+$ channels. Am. J. Physiol. Heart Circ. Physiol. 293, H1400-H1407. doi: 10.1152/ajpheart.00198.2007

Heinen, A., Ströthoff, M., Schmidt, A., Stracke, N., Behmenburg, F., Bauer, I., et al. (2014). Pharmacological options to protect the aged heart from ischemia and reperfusion injury by targeting the PKA-BKCa signaling pathway. Exp. Gerontol. 56, 99-105. doi: 10.1016/j.exger.2014.03.029

Heppner, T. J., Bonev, A. D., and Nelson, M. T. (1997). Ca(2+)-activated K+ channels regulate action potential repolarization in urinary bladder smooth muscle. Am. J. Physiol. 273(1 Pt 1), C110-C117.

Herrera, G. M., Etherton, B., Nausch, B., and Nelson, M. T. (2005). Negative feedback regulation of nerve-mediated contractions by $\mathrm{KCa}$ channels in mouse urinary bladder smooth muscle. Am. J. Physiol. Regul. Integr. Comp. Physiol. 289, R402-R409. doi: 10.1152/ajpregu.00488.2004

Herrera, G. M., Heppner, T. J., and Nelson, M. T. (2000). Regulation of urinary bladder smooth muscle contractions by ryanodine receptors and BK and SK channels. Am. J. Physiol. Regul. Integr. Comp. Physiol. 279, R60-R68.

Herrera, G. M., and Nelson, M. T. (2002). Differential regulation of SK and BK channels by $\mathrm{Ca}(2+)$ signals from $\mathrm{Ca}(2+)$ channels and ryanodine receptors in guinea-pig urinary bladder myocytes. J. Physiol. 541(Pt 2), 483-492. doi: 10.1113/jphysiol.2002.017707

Holland, M., Langton, P. D., Standen, N. B., and Boyle, J. P. (1996). Effects of the BKCa channel activator, NS1619, on rat cerebral artery smooth muscle. Br. J. Pharmacol. 117, 119-129. doi: 10.1111/j.1476-5381.1996.tb15163.x

Hoshi, T., Tian, Y., Xu, R., Heinemann, S. H., and Hou, S. (2013a). Mechanism of the modulation of BK potassium channel complexes with different auxiliary subunit compositions by the omega-3 fatty acid DHA. Proc. Natl. Acad. Sci. U.S.A. 110, 4822-4827. doi: 10.1073/pnas.1222003110

Hoshi, T., Wissuwa, B., Tian, Y., Tajima, N., Xu, R., Bauer, M., et al. (2013b). Omega-3 fatty acids lower blood pressure by directly activating largeconductance $\mathrm{Ca}^{2+}$-dependent $\mathrm{K}^{+}$channels. Proc. Natl. Acad. Sci. U.S.A. 110, 4816-4821. doi: 10.1073/pnas.1221997110

Hosseinzadeh, Z., Almilaji, A., Honisch, S., Pakladok, T., Liu, G., Bhavsar, S. K., et al. (2014). Upregulation of the large conductance voltage- and Ca2+-activated K+ channels by Janus kinase 2. Am. J. Physiol. Cell Physiol. 306, C1041-C1049. doi: 10.1152/ajpcell.00209.2013

Hou, S., Heinemann, S. H., and Hoshi, T. (2009). Modulation of BKCa channel gating by endogenous signaling molecules. Physiology (Bethesda) 24, 26-35. doi: 10.1152/physiol.00032.2008

Hou, S., Vigeland, L. E., Zhang, G., Xu, R., Li, M., Heinemann, S. H., et al. (2010). $\mathrm{Zn} 2+$ activates large conductance Ca2+-activated $\mathrm{K}+$ channel via an intracellular domain. J. Biol. Chem. 285, 6434-6442. doi: 10.1074/jbc.M109.069211

Hristov, K. L., Afeli, S. A. Y., Parajuli, S. P., Cheng, Q., Rovner, E. S., and Petkov, G. V. (2013). Neurogenic detrusor overactivity is associated with decreased expression and function of the large conductance voltage- and $\mathrm{Ca}(2+)$-activated $\mathrm{K}(+)$ channels. PLoS ONE 8:e68052. doi: 10.1371/journal.pone.0068052

Hristov, K. L., Chen, M., Kellett, W. F., Rovner, E. S., and Petkov, G. V. (2011). Large-conductance voltage- and $\mathrm{Ca} 2+$-activated $\mathrm{K}+$ channels regulate human detrusor smooth muscle function. Am. J. Physiol. Cell Physiol. 301, C903-C912. doi: 10.1152/ajpcell.00495.2010

Hristov, K. L., Parajuli, S. P., Soder, R. P., Cheng, Q., Rovner, E. S., and Petkov, G. V. (2012). Suppression of human detrusor smooth muscle excitability and contractility via pharmacological activation of large conductance $\mathrm{Ca} 2+$-activated K+ channels. Am. J. Physiol. Cell Physiol. 302, C1632-C1641. doi: 10.1152/ajpcell.00417.2011

Hristov, K. L., Smith, A. C., Parajuli, S. P., Malysz, J., and Petkov, G. V. (2014). Large-conductance voltage- and $\mathrm{Ca} 2+$-activated $\mathrm{K}+$ channel regulation by protein kinase $\mathrm{C}$ in guinea pig urinary bladder smooth muscle. Am. J. Physiol. Cell Physiol. 306, C460-C470. doi: 10.1152/ajpcell.00325.2013

Hu, Y., Yang, G., Xiao, X., Liu, L., and Li, T. (2014). Bkca opener, NS1619 pretreatment protects against shock-induced vascular hyporeactivity through PDZ-Rho
GEF-RhoA-Rho kinase pathway in rats. J. Trauma Acute Care Surg. 76, 394-401. doi: 10.1097/TA.0b013e3182aa2d98

Huang, C.-W., Huang, C.-C., and Wu, S.-N. (2007). Activation by zonisamide, a newer antiepileptic drug, of large-conductance calcium-activated potassium channel in differentiated hippocampal neuron-derived H19-7 cells. J. Pharmacol. Exp. Ther. 321, 98-106. doi: 10.1124/jpet.106.116954

Imai, T., Okamoto, T., Yamamoto, Y., Tanaka, H., Koike, K., Shigenobu, K., et al. (2001). Effects of different types of $\mathrm{K}+$ channel modulators on the spontaneous myogenic contraction of guinea-pig urinary bladder smooth muscle. Acta Physiol. Scand. 173, 323-333. doi: 10.1046/j.1365-201X.2001.00908.x

Jeffries, O., Geiger, N., Rowe, I. C. M., Tian, L., McClafferty, H., Chen, L., et al. (2010). Palmitoylation of the S0-S1 linker regulates cell surface expression of voltage- and calcium-activated potassium (BK) channels. J. Biol. Chem. 285, 33307-33314. doi: 10.1074/jbc.M110.153940

Jentsch, T. J. (2000). Neuronal KCNQ potassium channels: physiology and role in disease. Nat. Rev. Neurosci. 1, 21-30. doi: 10.1038/35036198

Jiang, Y., Lee, A., Chen, J., Cadene, M., Chait, B. T., and MacKinnon, R. (2002). Crystal structure and mechanism of a calcium-gated potassium channel. Nature 417, 515-522. doi: 10.1038/417515a

Keeley, E. C., Boura, J. A., and Grines, C. L. (2003). Primary angioplasty versus intravenous thrombolytic therapy for acute myocardial infarction: a quantitative review of 23 randomised trials. Lancet 361, 13-20. doi: 10.1016/S01406736(03)12113-7

King, J. T., Lovell, P. V., Rishniw, M., Kotlikoff, M. I., Zeeman, M. L., and McCobb, D. P. (2006). Beta2 and beta4 subunits of BK channels confer differential sensitivity to acute modulation by steroid hormones. J. Neurophysiol. 95, 2878-2888. doi: 10.1152/jn.01352.2005

Király, I., Pataricza, J., Bajory, Z., Simonsen, U., Varro, A., Papp, J. G., et al. (2013). Involvement of large-conductance $\mathrm{Ca}(2+)$-activated $\mathrm{K}(+)$ channels in both nitric oxide and endothelium-derived hyperpolarization-type relaxation in human penile small arteries. Basic Clin. Pharmacol. Toxicol. 113, 19-24. doi: 10.1111/bcpt.12059

Kirby, R. W., Martelli, A., Calderone, V., McKay, N. G., and Lawson, K. (2013). Large conductance $\mathrm{Ca}(2+)$-activated $\mathrm{K}(+)$ channel $(\mathrm{BKCa})$ activating properties of a series of novel $\mathrm{N}$-arylbenzamides: channel subunit dependent effects. Bioorg. Med. Chem. 21, 4186-4191. doi: 10.1016/j.bmc.2013.05.003

Knaus, H. G., Folander, K., Garcia-Calvo, M., Garcia, M. L., Kaczorowski, G. J., Smith, M., et al. (1994). Primary sequence and immunological characterization of beta-subunit of high conductance $\mathrm{Ca}(2+)$-activated $\mathrm{K}+$ channel from smooth muscle. J. Biol. Chem. 269, 17274-17278.

Knaus, H. G., Schwarzer, C., Koch, R. O., Eberhart, A., Kaczorowski, G. J., Glossmann, H., et al. (1996). Distribution of high-conductance $\mathrm{Ca}(2+)$ activated $\mathrm{K}+$ channels in rat brain: targeting to axons and nerve terminals. $J$. Neurosci. 16, 955-963.

Kobayashi, H., Adachi-Akahane, S., and Nagao, T. (2000). Involvement of BK(Ca) channels in the relaxation of detrusor muscle via beta-adrenoceptors. Eur. J. Pharmacol. 404, 231-238. doi: 10.1016/S0014-2999(00)00606-3

Kulawiak, B., Kudin, A. P., Szewczyk, A., and Kunz, W. S. (2008). BK channel openers inhibit ROS production of isolated rat brain mitochondria. Exp. Neurol. 212, 543-547. doi: 10.1016/j.expneurol.2008.05.004

Kun, A., Matchkov, V. V., Stankevicius, E., Nardi, A., Hughes, A. D., Kirkeby, H. J., et al. (2009). NS11021, a novel opener of large-conductance $\mathrm{Ca}(2+)$ activated $\mathrm{K}(+)$ channels, enhances erectile responses in rats. $\mathrm{Br}$. J. Pharmacol. 158, 1465-1476. doi: 10.1111/j.1476-5381.2009.00404.x

La Fuente, J. M., Fernández, A., Cuevas, P., González-Corrochano, R., Chen, M. X., and Angulo, J. (2014). Stimulation of large-conductance calcium-activated potassium channels inhibits neurogenic contraction of human bladder from patients with urinary symptoms and reverses acetic acid-induced bladder hyperactivity in rats. Eur. J. Pharmacol. 735, 68-76. doi: 10.1016/j.ejphar.2014.03.060

Layne, J. J., Nausch, B., Olesen, S.-P., and Nelson, M. T. (2010). BK channel activation by NS11021 decreases excitability and contractility of urinary bladder smooth muscle. Am. J. Physiol. Regul. Integr. Comp. Physiol. 298, R378-R384. doi: 10.1152/ajpregu.00458.2009

Liu, H., Xin, T., He, W., Li, F., and Su, Z.-Q. (2014). Myelinated Ah-type trigeminal ganglion neurons in female rats: neuroexcitability, chemosensitivity to histamine, and potential clinical impact. Neurosci. Lett. 567, 74-79. doi: 10.1016/j.neulet.2014.03.039

Liu, R., Zhang, Z., Liu, H., Hou, P., Lang, J., Wang, S., et al. (2013). Human $\beta$-defensin 2 is a novel opener of $\mathrm{Ca} 2+$-activated potassium channels and 
induces vasodilation and hypotension in monkeys. Hypertension 62, 415-425. doi: 10.1161/HYPERTENSIONAHA.111.01076

Liu, Y. C., Lo, Y. K., and Wu, S. N. (2003). Stimulatory effects of chlorzoxazone, a centrally acting muscle relaxant, on large conductance calcium-activated potassium channels in pituitary GH3 cells. Brain Res. 959, 86-97. doi: 10.1016/S00068993(02)03730-7

Lu, R., Lukowski, R., Sausbier, M., Zhang, D. D., Sisignano, M., Schuh, C.-D., et al. (2014). BKCa channels expressed in sensory neurons modulate inflammatory pain in mice. Pain 155, 556-565. doi: 10.1016/j.pain.2013.12.005

Magleby, K. L. (2003). Gating mechanism of BK (Slo1) channels: so near, yet so far. J. Gen. Physiol. 121, 81-96. doi: 10.1085/jgp.20028721

Malysz, J., Buckner, S. A., Daza, A. V., Milicic, I., Perez-Medrano, A., and Gopalakrishnan, M. (2004). Functional characterization of large conductance calcium-activated $\mathrm{K}+$ channel openers in bladder and vascular smooth muscle. Naunyn Schmiedebergs Arch. Pharmacol. 369, 481-489. doi: 10.1007/s00210004-0920-y

Malysz, J., Rovner, E. S., and Petkov, G. V. (2013). Single-channel biophysical and pharmacological characterizations of native human large-conductance calciumactivated potassium channels in freshly isolated detrusor smooth muscle cells. Pflügers Arch. 465, 965-975. doi: 10.1007/s00424-012-1214-8

Marrion, N. V., and Tavalin, S. J. (1998). Selective activation of Ca2+-activated K+ channels by co-localized Ca2+ channels in hippocampal neurons. Nature 395, 900-905. doi: 10.1038/27674

McManus, O. B., Harris, G. H., Giangiacomo, K. M., Feigenbaum, P., Reuben, J. P., Addy, M. E., et al. (1993). An activator of calcium-dependent potassium channels isolated from a medicinal herb. Biochemistry (Mosc.) 32, 6128-6133. doi: 10.1021/bi00075a002

McManus, O. B., Helms, L. M., Pallanck, L., Ganetzky, B., Swanson, R., and Leonard, R. J. (1995). Functional role of the beta subunit of high conductance calcium-activated potassium channels. Neuron 14, 645-650. doi: 10.1016/08966273(95) $90321-6$

Meera, P., Wallner, M., Song, M., and Toro, L. (1997). Large conductance voltageand calcium-dependent $\mathrm{K}+$ channel, a distinct member of voltage-dependent ion channels with seven $\mathrm{N}$-terminal transmembrane segments (S0-S6), an extracellular N terminus, and an intracellular (S9-S10) C terminus. Proc. Natl. Acad. Sci. U.S.A. 94, 14066-14071. doi: 10.1073/pnas.94.25.14066

Meera, P., Wallner, M., and Toro, L. (2000). A neuronal beta subunit (KCNMB4) makes the large conductance, voltage- and Ca2+-activated $\mathrm{K}+$ channel resistant to charybdotoxin and iberiotoxin. Proc. Natl. Acad. Sci. U.S.A. 97, 5562-5567. doi: 10.1073/pnas.100118597

Meredith, A. L., Thorneloe, K. S., Werner, M. E., Nelson, M. T., and Aldrich, R. W. (2004). Overactive bladder and incontinence in the absence of the BK large conductance Ca2+-activated K+ channel. J. Biol. Chem. 279, 36746-36752. doi: 10.1074/jbc.M405621200

Meredith, A. L., Wiler, S. W., Miller, B. H., Takahashi, J. S., Fodor, A. A., Ruby, N. F., et al. (2006). BK calcium-activated potassium channels regulate circadian behavioral rhythms and pacemaker output. Nat. Neurosci. 9, 1041-1049. doi: $10.1038 / \mathrm{nn} 1740$

Mora, T. C., and Suarez-Kurtz, G. (2005). Effects of NS1608, a BK(Ca) channel agonist, on the contractility of guinea-pig urinary bladder in vitro. Br. J. Pharmacol. 144, 636-641. doi: 10.1038/sj.bjp.0706034

Morimoto, T., Sakamoto, K., Sade, H., Ohya, S., Muraki, K., and Imaizumi, Y. (2007). Voltage-sensitive oxonol dyes are novel large-conductance Ca2+activated $\mathrm{K}+$ channel activators selective for betal and beta4 but not for beta2 subunits. Mol. Pharmacol. 71, 1075-1088. doi: 10.1124/mol.106.031146

Murry, C. E., Jennings, R. B., and Reimer, K. A. (1986). Preconditioning with ischemia: a delay of lethal cell injury in ischemic myocardium. Circulation 74, 1124-1136. doi: 10.1161/01.CIR.74.5.1124

N'Gouemo, P. (2011). Targeting BK (big potassium) channels in epilepsy. Expert Opin. Ther. Targets 15, 1283-1295. doi: 10.1517/14728222.2011.620607

Nardi, A., Calderone, V., Chericoni, S., and Morelli, I. (2003). Natural modulators of large-conductance calcium-activated potassium channels. Planta Med. 69, 885-892. doi: 10.1055/s-2003-45095

Nardi, A., and Olesen, S.-P. (2008). BK channel modulators: a comprehensive overview. Curr. Med. Chem. 15, 1126-1146. doi: 10.2174/092986708784221412

Nausch, B., Rode, F., Jorgensen, S., Nardi, A., Korsgaard, M. P. G., Hougaard, C., et al. (2014). NS19504: a novel BK channel activator with relaxing effect on bladder smooth muscle spontaneous phasic contractions. J. Pharmacol. Exp. Ther. 350, 520-530. doi: 10.1124/jpet.113.212662
Nelson, M. T., Cheng, H., Rubart, M., Santana, L. F., Bonev, A. D., Knot, H. J., et al. (1995). Relaxation of arterial smooth muscle by calcium sparks. Science 270, 633-637. doi: 10.1126/science.270.5236.633

Nicot, A., Berod, A., and Rostene, W. (1992). Distribution of preproneurotensin/neuromedin N mRNA in the young and adult rat forebrain. Ann. N.Y. Acad. Sci. 668, 361-364. doi: 10.1111/j.1749-6632.1992.tb27377.x

Oger, S., Behr-Roussel, D., Gorny, D., Bernabé, J., Comperat, E., Chartier-Kastler, E., et al. (2011). Effects of potassium channel modulators on myogenic spontaneous phasic contractile activity in human detrusor from neurogenic patients. BJU Int. 108, 604-611. doi: 10.1111/j.1464-410X.2010.09935.x

Ohi, Y., Yamamura, H., Nagano, N., Ohya, S., Muraki, K., Watanabe, M., et al. (2001). Local $\mathrm{Ca}(2+)$ transients and distribution of BK channels and ryanodine receptors in smooth muscle cells of guinea-pig vas deferens and urinary bladder. J. Physiol. 534(Pt 2), 313-326. doi: 10.1111/j.1469-7793.2001.t01-3-00313.x

Ohya, S., Kimura, S., Kitsukawa, M., Muraki, K., Watanabe, M., and Imaizumi, Y. (2000). SK4 encodes intermediate conductance Ca2+-activated K+ channels in mouse urinary bladder smooth muscle cells. Jpn. J. Pharmacol. 84, 97-100. doi: $10.1254 /$ jjp. 84.97

Ohya, S., Kuwata, Y., Sakamoto, K., Muraki, K., and Imaizumi, Y. (2005). Cardioprotective effects of estradiol include the activation of large-conductance $\mathrm{Ca}(2+)$-activated $\mathrm{K}(+)$ channels in cardiac mitochondria. Am. J. Physiol. Heart Circ. Physiol. 289, H1635-H1642. doi: 10.1152/ajpheart.00016.2005

Olesen, S. P., Munch, E., Moldt, P., and Drejer, J. (1994b). Selective activation of $\mathrm{Ca}(2+)$-dependent $\mathrm{K}+$ channels by novel benzimidazolone. Eur. J. Pharmacol. 251, 53-59. doi: 10.1016/0014-2999(94)90442-1

Olesen, S. P., Munch, E., Wätjen, F., and Drejer, J. (1994a). NS004-an activator of $\mathrm{Ca}(2+)$-dependent $\mathrm{K}+$ channels in cerebellar granule cells. Neuroreport 5, 1001-1004. doi: 10.1097/00001756-199404000-00037

Pacheco Otalora, L. F., Hernandez, E. F., Arshadmansab, M. F., Francisco, S., Willis, M., Ermolinsky, B., et al. (2008). Down-regulation of BK channel expression in the pilocarpine model of temporal lobe epilepsy. Brain Res. 1200, 116-131. doi: 10.1016/j.brainres.2008.01.017

Pallanck, L., and Ganetzky, B. (1994). Cloning and characterization of human and mouse homologs of the Drosophila calcium-activated potassium channel gene, slowpoke. Hum. Mol. Genet. 3, 1239-1243. doi: 10.1093/hmg/3.8.1239

Parajuli, S. P., Hristov, K. L., Cheng, Q., Malysz, J., Rovner, E. S., and Petkov, G. V. (2014b). Functional link between muscarinic receptors and large-conductance $\mathrm{Ca}(2+)$-activated $\mathrm{K}(+)$ channels in freshly isolated human detrusor smooth muscle cells. Pflugers Arch. doi: 10.1007/s00424-014-1537-8

Parajuli, S. P., Provence, A., and Petkov, G. V. (2014a). Prostaglandin E2 excitatory effects on guinea pig urinary bladder smooth muscle: a novel regulatory mechanism mediated by large-conductance voltage- and $\mathrm{Ca}(2+)$-activated K(+) channels. Eur. J. Pharmacol. 738C, 179-185. doi: 10.1016/j.ejphar.2014. 05.042

Park, W. S., Kang, S. H., Son, Y. K., Kim, N., Ko, J.-H., Kim, H. K., et al. (2007). The mitochondrial Ca2+-activated K+ channel activator, NS1619 inhibits L-type $\mathrm{Ca} 2+$ channels in rat ventricular myocytes. Biochem. Biophys. Res. Commun. 362, 31-36. doi: 10.1016/j.bbrc.2007.07.057

Pérez, G. J., Desai, M., Anderson, S., and Scornik, F. S. (2013). Large-conductance calcium-activated potassium current modulates excitability in isolated canine intracardiac neurons. Am. J. Physiol. Cell Physiol. 304, C280-C286. doi: 10.1152/ajpcell.00148.2012

Petkov, G. V. (2014). Central role of the BK channel in urinary bladder smooth muscle physiology and pathophysiology. Am. J. Physiol. Regul. Integr. Comp. Physiol. 307, R571-R584. doi: 10.1152/ajpregu.00142.2014

Petkov, G. V., Bonev, A. D., Heppner, T. J., Brenner, R., Aldrich, R. W., and Nelson, M. T. (2001). Beta1-subunit of the Ca2+-activated $\mathrm{K}+$ channel regulates contractile activity of mouse urinary bladder smooth muscle. J. Physiol. 537(Pt 2), 443-452. doi: 10.1111/j.1469-7793.2001.00443.x

Piwonska, M., Wilczek, E., Szewczyk, A., and Wilczynski, G. M. (2008). Differential distribution of $\mathrm{Ca} 2+$-activated potassium channel beta4 subunit in rat brain: immunolocalization in neuronal mitochondria. Neuroscience 153, 446-460. doi: 10.1016/j.neuroscience.2008.01.050

Plüger, S., Faulhaber, J., Fürstenau, M., Löhn, M., Waldschütz, R., Gollasch, M., et al. (2000). Mice with disrupted BK channel betal subunit gene feature abnormal $\mathrm{Ca}(2+)$ spark/STOC coupling and elevated blood pressure. Circ. Res. 87, E53-E60. doi: 10.1161/01.RES.87.11.e53

Ponte, C. G., McManus, O. B., Schmalhofer, W. A., Shen, D.-M., Dai, G., Stevenson, A., et al. (2012). Selective, direct activation of high-conductance, 
calcium-activated potassium channels causes smooth muscle relaxation. Mol. Pharmacol. 81, 567-577. doi: 10.1124/mol.111.075853

Redel, A., Lange, M., Jazbutyte, V., Lotz, C., Smul, T. M., Roewer, N., et al. (2008). Activation of mitochondrial large-conductance calcium-activated $\mathrm{K}+$ channels via protein kinase A mediates desflurane-induced preconditioning. Anesth. Analg. 106, 384-391. doi: 10.1213/ane.0b013e318160650f

Revermann, M., Neofitidou, S., Kirschning, T., Schloss, M., Brandes, R. P., and Hofstetter, C. (2014). Inhalation of the BK(Ca)-opener NS1619 attenuates right ventricular pressure and improves oxygenation in the rat monocrotaline model of pulmonary hypertension. PLoS ONE 9:e86636. doi: 10.1371/journal.pone. 0086636

Roy, S., Large, R. J., Akande, A. M., Kshatri, A., Webb, T. I., Domene, C., et al. (2014). Development of GoSlo-SR-5-69, a potent activator of large conductance Ca2+-activated K+ (BK) channels. Eur. J. Med. Chem. 75, 426-437. doi: 10.1016/j.ejmech.2014.01.035

Roy, S., Morayo Akande, A., Large, R. J., Webb, T. I., Camarasu, C., Sergeant, G. P., et al. (2012). Structure-activity relationships of a novel group of largeconductance $\mathrm{Ca}(2+)$-activated $\mathrm{K}(+)(\mathrm{BK})$ channel modulators: the GoSlo-SR family. Chem. Med. Chem. 7, 1763-1769. doi: 10.1002/cmdc.201200321

Rüttiger, L., Sausbier, M., Zimmermann, U., Winter, H., Braig, C., Engel, J., et al. (2004). Deletion of the Ca2+-activated potassium (BK) alpha-subunit but not the BKbetal-subunit leads to progressive hearing loss. Proc. Natl. Acad. Sci. U.S.A. 101, 12922-12927. doi: 10.1073/pnas.0402660101

Saleh, S. N., Angermann, J. E., Sones, W. R., Leblanc, N., and Greenwood, I. A. (2007). Stimulation of Ca2+-gated Cl- currents by the calciumdependent K+ channel modulators NS1619 [1, 3-dihydro-1-[2-hydroxy5-(trifluoromethyl)phenyl]-5-(trifluoromethyl)-2H-benzimidazol-2-one] and isopimaric acid. J. Pharmacol. Exp. Ther. 321, 1075-1084. doi: 10.1124/jpet.106. 118786

Salkoff, L., Butler, A., Ferreira, G., Santi, C., and Wei, A. (2006). High-conductance potassium channels of the SLO family. Nat. Rev. Neurosci. 7, 921-931. doi: $10.1038 / \mathrm{nrn} 1992$

Sato, T., Saito, T., Saegusa, N., and Nakaya, H. (2005). Mitochondrial Ca2+activated $\mathrm{K}+$ channels in cardiac myocytes: a mechanism of the cardioprotective effect and modulation by protein kinase A. Circulation 111, 198-203. doi: 10.1161/01.CIR.0000151099.15706.B1

Sausbier, M., Arntz, C., Bucurenciu, I., Zhao, H., Zhou, X.-B., Sausbier, U., et al. (2005). Elevated blood pressure linked to primary hyperaldosteronism and impaired vasodilation in BK channel-deficient mice. Circulation 112, 60-68. doi: 10.1161/01.CIR.0000156448.74296.FE

Sausbier, M., Hu, H., Arntz, C., Feil, S., Kamm, S., Adelsberger, H., et al. (2004). Cerebellar ataxia and Purkinje cell dysfunction caused by Ca2+-activated K+ channel deficiency. Proc. Natl. Acad. Sci. U.S.A. 101, 9474-9478. doi: 10.1073/pnas.0401702101

Sausbier, U., Sausbier, M., Sailer, C. A., Arntz, C., Knaus, H.-G., Neuhuber, W., et al. (2006). Ca2+-activated $\mathrm{K}+$ channels of the BK-type in the mouse brain. Histochem. Cell Biol. 125, 725-41. doi: 10.1007/s00418-005-0124-7

Scornik, F. S., Bucciero, R. S., Wu, Y., Selga, E., Bosch Calero, C., Brugada, R., et al. (2013). DiBAC4(3) hits a "sweet spot" for the activation of arterial large-conductance $\mathrm{Ca}^{2+}$-activated potassium channels independently of the B1-subunit. Am. J. Physiol. Heart Circ. Physiol. 304, H1471-H1482. doi: 10.1152/ajpheart.00939.2012

Sheehan, J. J., Benedetti, B. L., and Barth, A. L. (2009). Anticonvulsant effects of the BK-channel antagonist paxilline. Epilepsia 50, 711-720. doi: 10.1111/j.15281167.2008.01888.x

Shi, Y., Jiang, M. T., Su, J., Hutchins, W., Konorev, E., and Baker, J. E. (2007). Mitochondrial big conductance KCa channel and cardioprotection in infant rabbit heart. J. Cardiovasc. Pharmacol. 50, 497-502. doi: 10.1097/FJC.0b013e 318137991d

Shintani, Y., Node, K., Asanuma, H., Sanada, S., Takashima, S., Asano, Y., et al. (2004). Opening of Ca2+-activated $\mathrm{K}+$ channels is involved in ischemic preconditioning in canine hearts. J. Mol. Cell. Cardiol. 37, 1213-1218. doi: 10.1016/j.yjmcc.2004.09.012

Shipston, M. J. (2001). Alternative splicing of potassium channels: a dynamic switch of cellular excitability. Trends Cell Biol. 11, 353-358. doi: 10.1016/S09628924(01)02068-2

Shruti, S., Clem, R. L., and Barth, A. L. (2008). A seizure-induced gain-offunction in BK channels is associated with elevated firing activity in neocortical pyramidal neurons. Neurobiol. Dis. 30, 323-330. doi: 10.1016/j.nbd.2008.02.002
Singh, H., Lu, R., Bopassa, J. C., Meredith, A. L., Stefani, E., and Toro, L. (2013). MitoBK(Ca) is encoded by the Kcnmal gene, and a splicing sequence defines its mitochondrial location. Proc. Natl. Acad. Sci. U.S.A. 110, 10836-10841. doi: 10.1073/pnas.1302028110

Skalska, J., Bednarczyk, P., Piwońska, M., Kulawiak, B., Wilczynski, G., Dołowy, K., et al. (2009). Calcium ions regulate $\mathrm{K}^{+}$uptake into brain mitochondria: the evidence for a novel potassium channel. Int. J. Mol. Sci. 10, 1104-1120. doi: 10.3390/ijms10031104

Soder, R. P., and Petkov, G. V. (2011). Large conductance Ca2+ -activated K+ channel activation with NS1619 decreases myogenic and neurogenic contractions of rat detrusor smooth muscle. Eur. J. Pharmacol. 670, 252-259. doi 10.1016/j.ejphar.2011.08.013

Soltysinska, E., Bentzen, B. H., Barthmes, M., Hattel, H., Thrush, A. B., Harper, M.-E., et al. (2014). KCNMA1 Encoded Cardiac BK Channels Afford Protection against Ischemia-Reperfusion Injury. PLoS ONE 9:e103402. doi: 10.1371/journal.pone. 0103402

Spektor, M., Rodriguez, R., Rosenbaum, R. S., Wang, H.-Z., Melman, A., and Christ, G. J. (2002). Potassium channels and human corporeal smooth muscle cell tone: further evidence of the physiological relevance of the Maxi-K channel subtype to the regulation of human corporeal smooth muscle tone in vitro. J. Urol. 167, 2628-2635. doi: 10.1016/S0022-5347(05)65049-5

Sprossmann, F., Pankert, P., Sausbier, U., Wirth, A., Zhou, X.-B., Madlung, J., et al. (2009). Inducible knockout mutagenesis reveals compensatory mechanisms elicited by constitutive BK channel deficiency in overactive murine bladder. FEBS J. 276, 1680-1697. doi: 10.1111/j.1742-4658.2009.06900.x

Storm, J. F. (1987). Action potential repolarization and a fast afterhyperpolarization in rat hippocampal pyramidal cells. J. Physiol. 385, 733-759.

Stowe, D. F., Aldakkak, M., Camara, A. K. S., Riess, M. L., Heinen, A., Varadarajan, S. G., et al. (2006). Cardiac mitochondrial preconditioning by Big $\mathrm{Ca} 2+-$ sensitive $\mathrm{K}+$ channel opening requires superoxide radical generation. Am. J. Physiol. Heart Circ. Physiol. 290, H434-H440. doi: 10.1152/ajpheart.00763.2005

Swensen, A. M., and Bean, B. P. (2003). Ionic mechanisms of burst firing in dissociated Purkinje neurons. J. Neurosci. 23, 9650-9663.

Szabo, I., and Zoratti, M. (2014). Mitochondrial channels: ion fluxes and more. Physiol. Rev. 94, 519-608. doi: 10.1152/physrev.00021.2013

Thorneloe, K. S., Meredith, A. L., Knorn, A. M., Aldrich, R. W., and Nelson, M. T. (2005). Urodynamic properties and neurotransmitter dependence of urinary bladder contractility in the BK channel deletion model of overactive bladder. Am. J. Physiol. Renal Physiol. 289, F604-F610. doi: 10.1152/ajprenal.00060.2005

Tian, L., McClafferty, H., Knaus, H.-G., Ruth, P., and Shipston, M. J. (2012). Distinct acyl protein transferases and thioesterases control surface expression of calcium-activated potassium channels. J. Biol. Chem. 287, 14718-14725. doi: 10.1074/jbc.M111.335547

Toro, L., Li, M., Zhang, Z., Singh, H., Wu, Y., and Stefani, E. (2014). MaxiK channel and cell signalling. Pflügers Arch. Eur. J. Physiol. 466, 875-886. doi: 10.1007/s00424-013-1359-0

Uchida, H., Shishido, K., Nomiya, M., and Yamaguchi, O. (2005). Involvement of cyclic AMP-dependent and -independent mechanisms in the relaxation of rat detrusor muscle via beta-adrenoceptors. Eur. J. Pharmacol. 518, 195-202. doi: 10.1016/j.ejphar.2005.06.029

Valverde, M. A., Rojas, P., Amigo, J., Cosmelli, D., Orio, P., Bahamonde, M. I., et al. (1999). Acute activation of Maxi-K channels (hSlo) by estradiol binding to the beta subunit. Science 285, 1929-1931. doi: 10.1126/science.285.5435.1929

Vang, A., Mazer, J., Casserly, B., and Choudhary, G. (2010). Activation of endothelial BKCa channels causes pulmonary vasodilation. Vascul. Pharmacol. 53, 122-129. doi: 10.1016/j.vph.2010.05.001

Verma-Ahuja, S., Evans, M. S., and Pencek, T. L. (1995). Evidence for decreased calcium dependent potassium conductance in hippocampal CA3 neurons of genetically epilepsy-prone rats. Epilepsy Res. 22, 137-144. doi: 10.1016/09201211(95)00040-2

Wallner, M., Meera, P., and Toro, L. (1999). Molecular basis of fast inactivation in voltage and $\mathrm{Ca} 2+$-activated $\mathrm{K}+$ channels: a transmembrane beta-subunit homolog. Proc. Natl. Acad. Sci. U.S.A. 96, 4137-4142. doi: 10.1073/pnas.96.7.4137

Wang, X., Yin, C., Xi, L., and Kukreja, R. C. (2004). Opening of Ca2+-activated K+ channels triggers early and delayed preconditioning against I/R injury independent of NOS in mice. Am. J. Physiol. Heart Circ. Physiol. 287, H2070-H2077. doi: 10.1152/ajpheart.00431.2004 
Wang, Z., Subramanya, A. R., Satlin, L. M., Pastor-Soler, N. M., Carattino, M. D., and Kleyman, T. R. (2013). Regulation of large-conductance Ca2+-activated K+ channels by WNK4 kinase. Am. J. Physiol. Cell Physiol. 305, C846-C853. doi: 10.1152/ajpcell.00133.2013

Weaver, A. K., Olsen, M. L., McFerrin, M. B., and Sontheimer, H. (2007). BK channels are linked to inositol 1, 4, 5-triphosphate receptors via lipid rafts: a novel mechanism for coupling $[\mathrm{Ca}(2+)](\mathrm{i})$ to ion channel activation. J. Biol. Chem. 282, 31558-31568. doi: 10.1074/jbc.M702866200

Werner, M. E., Knorn, A.-M., Meredith, A. L., Aldrich, R. W., and Nelson, M. T. (2007). Frequency encoding of cholinergic- and purinergic-mediated signaling to mouse urinary bladder smooth muscle: modulation by BK channels. Am. J. Physiol. Regul. Integr. Comp. Physiol. 292, R616-R624. doi: 10.1152/ajpregu.00036.2006

Werner, M. E., Zvara, P., Meredith, A. L., Aldrich, R. W., and Nelson, M. T. (2005). Erectile dysfunction in mice lacking the large-conductance calcium-activated potassium (BK) channel. J. Physiol. 567(Pt 2), 545-556. doi: 10.1113/jphysiol.2005.093823

Wojtovich, A. P., Nadtochiy, S. M., Urciuoli, W. R., Smith, C. O., Grunnet, M., Nehrke, K., et al. (2013). A non-cardiomyocyte autonomous mechanism of cardioprotection involving the SLO1 BK channel. Peer J. 1:e48. doi: $10.7717 /$ peerj. 48

Wojtovich, A. P., Sherman, T. A., Nadtochiy, S. M., Urciuoli, W. R., Brookes, P. S., and Nehrke, K. (2011). SLO-2 is cytoprotective and contributes to mitochondrial potassium transport. PLoS ONE 6:e28287. doi: 10.1371/journal.pone.0028287

Womack, M. D., and Khodakhah, K. (2004). Dendritic control of spontaneous bursting in cerebellar Purkinje cells. J. Neurosci. 24, 3511-3521. doi: 10.1523/JNEUROSCI.0290-04.2004

Wu, S.-N., Liu, S.-I., and Huang, M.-H. (2004). Cilostazol, an inhibitor of type 3 phosphodiesterase, stimulates large-conductance, calcium-activated potassium channels in pituitary GH3 cells and pheochromocytoma PC12 cells. Endocrinology 145, 1175-1184. doi: 10.1210/en.2003-1430

Wulf-Johansson, H., Amrutkar, D. V., Hay-Schmidt, A., Poulsen, A. N., Klaerke, D. A., Olesen, J., et al. (2010). Localization of large conductance calciumactivated potassium channels and their effect on calcitonin gene-related peptide release in the rat trigemino-neuronal pathway. Neuroscience 167, 1091-102. doi: 10.1016/j.neuroscience.2010.02.063
Xin, W., Li, N., Cheng, Q., and Petkov, G. V. (2014). BK channel-mediated relaxation of urinary bladder smooth muscle: a novel paradigm for phosphodiesterase type 4 regulation of bladder function. J. Pharmacol. Exp. Ther. 349, 56-65. doi: 10.1124/jpet.113.210708

Xu, W., Liu, Y., Wang, S., McDonald, T., Van Eyk, J. E., Sidor, A., et al. (2002). Cytoprotective role of $\mathrm{Ca} 2+-$ activated $\mathrm{K}+$ channels in the cardiac inner mitochondrial membrane. Science 298, 1029-1033. doi: 10.1126/science.1074360

Yan, J., and Aldrich, R. W. (2010). LRRC26 auxiliary protein allows BK channel activation at resting voltage without calcium. Nature 466, 513-516. doi: 10.1038/nature09162

Yan, J., and Aldrich, R. W. (2012). BK potassium channel modulation by leucinerich repeat-containing proteins. Proc. Natl. Acad. Sci. U.S.A. 109, 7917-7922. doi: 10.1073/pnas.1205435109

Yan, J., Olsen, J. V., Park, K.-S., Li, W., Bildl, W., Schulte, U., et al. (2008). Profiling the phospho-status of the BKCa channel alpha subunit in rat brain reveals unexpected patterns and complexity. Mol Cell Proteomics 7, 2188-2198. doi: 10.1074/mcp.M800063-MCP200

Yellon, D. M., and Hausenloy, D. J. (2007). Myocardial reperfusion injury. N. Engl. J. Med. 357, 1121-1135. doi: 10.1056/NEJMra071667

Conflict of Interest Statement: The authors declare that the research was conducted in the absence of any commercial or financial relationships that could be construed as a potential conflict of interest.

Received: 11 July 2014; accepted: 19 September 2014; published online: 09 October 2014.

Citation: Bentzen BH, Olesen S-P, Rønn LCB and Grunnet M (2014) BK channel activators and their therapeutic perspectives. Front. Physiol. 5:389. doi: 10.3389/fphys. 2014.00389

This article was submitted to Membrane Physiology and Membrane Biophysics, a section of the journal Frontiers in Physiology.

Copyright (c) 2014 Bentzen, Olesen, Rønn and Grunnet. This is an open-access article distributed under the terms of the Creative Commons Attribution License (CC BY).

The use, distribution or reproduction in other forums is permitted, provided the original author(s) or licensor are credited and that the original publication in this journal is cited, in accordance with accepted academic practice. No use, distribution or reproduction is permitted which does not comply with these terms. 